\title{
Arthritis in Infancy
}

Sir,

We read with interest the clinical brief titled "Systemic onset juvenile idiopathic arthritis-Its unusual presentation?"1 Arthritis in infancy always poses a diagnostic dilemma in pediatric rheumatology services. The authors have correctly ruled out close mimics of systemic onset juvenile idiopathic arthritis including NOMID/CINCA (Neonatal onset multisystem inflammatory disease/ chronic infantile neurologic, cutaneous and articular) syndrome. We have comments on the exclusion factors for NOMID in the index case:

1) Absence of neurological symptoms- A mutation positive NOMID reported by the authors ${ }^{2}$ also had no neurological symptomatology and this is also known to evolve with time. Other corroborative evidence for NOMID - developmental milestones (especially vision \& hearing), detailed opthalmological evaluation (optic disc changes), neuroimaging have not been done/mentioned.

2) Similarly, chronic meningitis may not be present in NOMID. ${ }^{2,3}$

3) A typical arthropathy- the patellar overgrowth with unique radiologic changes is observed in about half of the cases. ${ }^{3}$

Subcutaneous nodule in the index case ${ }^{1}$ has not been discribed in NOMID patients.
TABle 1. Common Typical Differentiating Features Between SOJIA and NOMID/CINCA

\begin{tabular}{lll}
\hline Features & CINCA/NOMID & SOJIA \\
\hline $\begin{array}{l}\text { Age at onset } \\
\text { Usual Rash }\end{array}$ & $\begin{array}{l}\text { Neonate/ Infancy } \\
\text { Persistent, non-pruritic } \\
\text { migratory }\end{array}$ & $\begin{array}{l}\text { > 1 year } \\
\text { Evanescent } \\
\text { with fever } \\
\text { Absent }\end{array}$ \\
$\begin{array}{l}\text { Central nervous } \\
\text { system }\end{array}$ & $\begin{array}{l}\text { Patellar overgrowth, } \\
\text { Joints } \\
\text { metaphyseal \& } \\
\text { long bones }\end{array}$ & Any \\
Optic disc changes & $\begin{array}{l}\text { Anterior uveitis } \\
\text { (with posterior } \\
\text { synechiae, glaucoma, } \\
\text { cataracts) } \\
\text { Not known }\end{array}$ \\
Etiology & $\begin{array}{l}\text { C1AS1 mutation on } \\
\text { chromosome 1 }\end{array}$ & \\
\hline
\end{tabular}

Chetna Khemani and Raju Khubchandani Pediatric Rhematology Clinic, Jaslok Hospital \& Research Center, Mumbai, India

E-mail: chetnakhemani@yahoo.com

[DOI-10.1007/s12098-009-0311-y]

\section{REFERENCES}

1. Ghosh JB, Gupta D, Chattopadhyay N. Systemic onset juvenile idiopathic arthritis. Indian J Pediatr 2008; 75:98-100.

2. Khemani C, Khubchandani R. CINCA syndrome.Indian Pediatr 2007; 44: 933-936.

3. Prieur AM. A recently recognized chronic inflammatory disease of early onset characterized by the triad of rash, central nervous system involvement and arthropathy. Clin Exp Rheumatol 2001;19: 103-106.

\section{Author's Reply}

Sir,

Thanks to the readers for active interest in our article to give the comments on exclusion factors for NOMID. Absence of neurological symptoms in one mutation positive NOMID does not necessarily indicate that our case was also NOMID with absence of neuro deficit. NOMID/CINCA syndrome is a chronic inflammatory disease characterized by a triad of cutaneous rash, chronic meningitis and arthropathy. I fully agree that chronic meningitis is not seen in $100 \%$ NOMID patients but in nearly all NOMID patients progressive neurological signs developed. The rest of the clinical examination was non contributory-mentioned in our article is a pointer towards other corroborative evidence for NOMID like developmental mildstones especially vision and hearig optic disk changes were absent in our case. The neurodeficits including optic disk changes are mostly related to chronic maningitis which was not at all evident clinically in our case. For this reason and economic constraint of the parents neuroimaging was not done.

Though arthropathy is seen in 50-60\% in NOMID patients, the radioimaging finding of knee is seen as deform femora and patella due to bony overgrowth in all the patients with arthropathy without evidence of synovitis.

Reader have agreed that subcutaneous nodule in the index case has not been mentioned in NOMID patient. So presence of subcutaneous nodule in our case also strongly raises doubt the possibility of NOMID.

\section{JB Ghosh}

Professor, Ushashi Housing Society, 245, Vivekananda Road Kolkata-700 006, West Bengal, India. E-mail: jbghosh@yahoo.com 